\title{
SUSCEPTIBILITY TO PSORIASIS VULGARIS IS CONTROLLED IN PART BY TWO UNLINKED GENES IN A DOUBLE RECESSIVE MANNER
}

\author{
Masahiko Muto, ${ }^{1}$ Norikazu Yasuda, ${ }^{2}$ Hideto Kimura, ${ }^{1}$ \\ Yoshio NAKAMIzo, ${ }^{1}$ and Takehiko SASAZUKI ${ }^{3}$ \\ ${ }^{1}$ Department of Clinical Genetics, Medical Institute of Bioregulation, \\ Kyushu University, Tsurumiharu, Beppu 874, Japan \\ ${ }^{2}$ Division of Genetics, National Institute of Radiological Sciences, \\ Anagawa, Chiba 260, Japan \\ ${ }^{3}$ Department of Genetics, Medical Institute of Bioregulation, \\ Kyushu University, Maidashi, Higashi-ku, Fukuoka 812, Japan
}

\begin{abstract}
Summary The mode of inheritance of the susceptibility to psoriasis vulgaris (PV) was investigated by segregation analysis. Because our main aim was to search a possibility of the double recessive hypothesis for the disease susceptibility, we examined 83 families of normal $\times$ normal mating by single selection out of 93 probands, a number sufficient to be analyzed genetically. Nine of the 83 couples had two or more affected children, including probands. As to the 83 families, the hypothesis of the single recessive model for $\mathrm{PV}$ was ruled out, but the double recessive model allowing for 62 to $80 \%$ of sporadic cases was fitted to the family data. Penetrance value of the disease trait ranged from 33 to $43 \%$. It is thus likely that about 20 to $38 \%$ of patients with psoriasis are homozygous for two unlinked autosomal recessive genes.
\end{abstract}

Key Words psoriasis vulgaris, double recessive model, genetic heterogeneity

\section{INTRODUCTION}

It is well established that genetic factors are involved in the development of psoriasis vulgaris (PV) (Lomholt, 1976). However, the mode of inheritance of the susceptibility genes influencing PV has not been established. For Caucasians, monogenic, oligogenic and multifactorial inheritances have been reported (Steinberg

Received May 9, 1988; revised version received September 5, 1988; Accepted September 12, 1988 All correspondence to: Dr. Masahiko Muto, Department of Clinical Genetics, Medical Institute of Bioregulation, Kyushu University, 4546 Tsurumiharu, Beppu 874, Japan. 
et al., 1952; Abele et al., 1963; Watson et al., 1972). A genetic analysis of Japanese patients with the disease has rarely been reported.

Yasuda and Sasazuki (1984) developed a new genetic method, complex segregation analysis for a two-locus model. This approach implements the analyses of segregation frequency, ascertainment probability and proportion of sporadic cases for two major loci.

We used this method to analyze the inheritance of susceptibility to PV in a Japanese population.

\section{PATIENTS AND METHODS}

Patients. Ninety-three families with psoriasis were collected through 93 probands in the Dermatology Clinic of the Medical Institute of Bioregulation Hospital, Kyushu University. PV was diagnosed on clinical features by observing typical erythematous plaques with silvery scales distributed symmetrically and/or associated nail changes. Out of these 93, 83 families of normal $\times$ normal mating and seven families of normal $\times$ affected mating were ascertained through children (single selection) and three families of normal $\times$ affected mating were collected through parents (complete selection). Out of the 83 couples of normal $\times$ normal mating, nine had two or more affected children, including probands. The 83 psoriatic families were the subjects of the following study. The 83 probands had 353 siblings, including themselves. The overall numbers of psoriatic patients were 93 of $353(26.2 \%)$. Out of the 83 probands, $62(74.7 \%)$ were males. However, we found no significant sex difference in frequency (male : female $=1: 0.9$ ) of PV among the first-degree relatives of the 83 probands. On the basis of these observations, we assumed that a greater frequency of males among the psoriatic probands was probably due to an ascertainment bias.

Data analyses. Testing of the double recessive model was performed by complex segregation analysis, as described by Yasuda and Sasazuki (1984). This approach allows for possibility of the genetic heterogeneity of the disease. Gene frequencies of the two recessive genes in the double recessive model were estimated to be 0.197 , respectively, from the observed frequency of parents phenotypes.

\section{RESULTS}

Mode of inheritance for the susceptibility to PV

From the findings in affected children segregated from 83 couples of normal $x$ normal mating, there is the possibility that susceptibility to $P V$ is a single recessive event. However, the data did not fit a single recessive model with full penetrance $\left(\chi_{14}{ }^{2}=127.39 ; \mathrm{p}<1 \times 10^{-5}\right)$, under single ascertainment (Table 1). If one calculates the penetrance value under the single recessive model, then one can obtain only the low figure of $15 \%(0.037 / 0.25=0.15)$ since the expected and observed segregation 
Table 1. Tests of goodness-of-fit to a single recessive hypothesis for the susceptibility to PV.

\begin{tabular}{|c|c|c|c|c|}
\hline Sibship size & $\begin{array}{l}\text { Numbers of } \\
\text { affected sibs }\end{array}$ & Observed & Expected & $x^{2}$ \\
\hline 1 & 1 & 2 & 2.00 & 0.00 \\
\hline 2 & 1 & 13 & 9.75 & 1.08 \\
\hline 2 & 2 & 0 & 3.25 & 3.25 \\
\hline 3 & 1 & 20 & 11.81 & 5.68 \\
\hline 3 & 2 & 1 & 7.88 & 6.01 \\
\hline 3 & 3 & 0 & 1.31 & 1.31 \\
\hline 4 & 1 & 12 & 7.17 & 3.25 \\
\hline 4 & 2 & 4 & 7.17 & 1.40 \\
\hline 4 & 3 & 1 & 2.39 & 0.81 \\
\hline 4 & 4 & 0 & 0.27 & 0.27 \\
\hline 5 & 1 & 9 & 3.16 & 10.79 \\
\hline 5 & 2 & 1 & 0.42 & 0.80 \\
\hline 5 & $3-5$ & 0 & 6.42 & 6.42 \\
\hline 6 & 1 & 4 & 1.19 & 6.64 \\
\hline 6 & 2 & 1 & 1.98 & 0.49 \\
\hline 6 & $3-6$ & 0 & 1.83 & 1.83 \\
\hline 7 & 1 & 7 & 1.42 & 21.93 \\
\hline 7 & 2 & 1 & 2.85 & 1.20 \\
\hline 7 & $3-7$ & 0 & 3.73 & 3.73 \\
\hline 8 & 1 & 6 & 0.80 & 33.80 \\
\hline 8 & $2-8$ & 0 & 5.20 & 5.20 \\
\hline 10 & 1 & 1 & 0.08 & 10.58 \\
\hline 10 & $2-10$ & 0 & 0.92 & 0.92 \\
\hline Total & & 83 & 83.00 & $\begin{array}{c}127.39^{*} \\
(\mathrm{df}=14)\end{array}$ \\
\hline
\end{tabular}

${ }^{*} \mathrm{p}<1 \times 10^{-5}$. a Probands are included.

frequencies are 0.25 and $0.037(10 / 270=0.037)$, respectively. Thus, the susceptibility to PV in these families cannot be explained by a single locus.

We then examined a goodness-of-fit to a double recessive model in this disease, since Steinberg et al. (1952) suggested that the susceptibility to PV might be a double recessive trait. The results of the segregation analysis are given in Table 2. The null hypothesis of a double recessive model (segregation frequency $=0.0625$, probability of ascertainment $=0$, and no sporadic cases) was rejected $\left(\chi_{14}{ }^{2}=91.68 ; p<1 \times\right.$ $\left.10^{-5}\right)$. However, there was no statistical significance $\left(\gamma_{12}{ }^{2}=11.52 ; p>0.40\right)$ under the hypothesis (maximum likelihood estimate of segregation frequency $=0.0270$, probability of ascertainment $=0$, and maximum estimate of proportion of sporadic 
Table 2. Complex segregation analysis of the susceptibility to PV under a double recessive mode of inheritance. ${ }^{\text {a }}$

\begin{tabular}{llllllll}
\hline Mating type & \multicolumn{1}{c}{$\mathrm{p}$} & $\mathrm{x}$ & $\pi$ & $\chi^{2}(\mathrm{df})$ & & Penetrance \\
\hline $\begin{array}{l}\text { Normal } \times \text { normal } \\
\quad \text { Simplex and multiplex } \\
\quad \text { families }(\mathrm{n}=83)\end{array}$ & 0.0625 & 0 & 0 & $91.68(14)$ & $\mathrm{p}<1 \times 10^{-5}$ & $100 \%$ \\
& $0.0270^{\mathrm{b}}$ & $0.62^{\mathrm{b}}$ & 0 & $11.52(12)$ & $\mathrm{p}>0.40$ & $43 \%$ \\
& 0.0625 & $0.80^{\mathrm{b}}$ & 0 & $11.44(13)$ & $\mathrm{p}>0.40$ & $100 \%$ \\
\hline $\begin{array}{l}\text { Normal } \times \text { normal } \\
\quad \text { Multiplex families }\end{array}$ & 0.0625 & - & 0 & $3.02(6)$ & $\mathrm{p}>0.70$ & $100 \%$ \\
$\quad$ alone $(\mathrm{n}=9)$ & $0.0210^{\mathrm{b}}$ & - & 0 & $1.59(5)$ & $\mathrm{p}>0.80$ & $33 \%$ \\
\hline
\end{tabular}

$\mathrm{p}$, segregation frequency; $\mathrm{x}$, proportion of sporadic cases; $\pi$, probability of ascertainment; $\chi^{2}$, goodness-of-fit of segregation distribution to the expectation. a Gene frequencies of the two recessive genes were estimated to be 0.197 , respectively. b Maximum likelihood estimate under each condition.

cases $=0.62)$. There was also no significance $\left(\chi_{13}{ }^{2}=11.44 ; p>0.40\right)$ under the hypothesis (segregation frequency $=0.0625$, probability of ascertainment $=0$, and maximum likelihood estimate of proportion of sporadic cases $=0.80$ ). These observations suggest that the susceptibility to PV is highly heterogeneous $(62-80 \%)$ and that about $20-38 \%$ of patients with PV are homozygous for two unlinked autosomal recessive genes. On the other hand, with nine psoriatic multiplex families, there was no statistical difference between the expectation and the observation in the distribution of the psoriatics $\left(\chi_{6}{ }^{2}=3.02 ; \mathrm{p}>0.70\right)$ under the null hypothesis of a double recessive model (segregation frequency $=0.0625$, probability of ascertainment $=0$ ). The estimated segregation frequency $(0.0210)$ in the nine psoriatic multiplex families differed little from that $(0.0270)$ in the 83 psoriatic families. Thus, the penetrance of the disease trait was estimated to be $33-43 \%$.

\section{DISCUSSION}

Among a sample of 93 psoriatic families through 93 probands, we examined 83 families of normal $\times$ normal mating for segregation analysis. Our main aim in this work was to search for possible evidence of a double recessive model for this susceptibility to PV. If we use 7 families of normal $\times$ affected mating collected through children, we can obtain the data $\left(\chi_{1}^{2}=0.44 ; \mathrm{p}>0.70\right)$ fitted to the double recessive model (segregation frequency $=0.25$, maximum likelihood estimate of sporadic cases $=0.75$, and ascertainment of probability $=0$ ). In addition, if we use 3 normal $\times$ affected mating families collected through parents, we get a similar result $\left(\chi_{2}{ }^{2}=3.51 ; p>0.10\right)$ under the double recessive model (segregation frequency $=0.25$, proportion of nonsegregating family $=0$, and ascertainment of probability $=1$ ). 
These results enable a discussion on the mode of inheritance to PV in 83 families of normal $\times$ normal mating, a number sufficient to be analyzed genetically. In our sample of 83 psoriatic families, about 20 to $38 \%$ of the susceptibility to PV might be homozygous on two unlinked autosomal recessive genes. However, a much larger proportion $(62$ to $80 \%$ ) is due to an apparent genetic heterogeneity on the susceptibility to PV. Some investigators favored a genetic heterogeneity in PV (Farber and Nall, 1974; Pietrzyk et al., 1982; Iselius and Williams, 1984; Henseler and Christophers, 1985). For this reason, several hypotheses have been proposed (Steinberg et al., 1952; Abele et al., 1963; Watson et al., 1972).

Our results are based on the assumption that gene frequencies of the two unlinked autosomal recessive genes are even, as is the case with PV analyzed by Steinberg et al. (1952). The accuracy of this assumption has not been established. One way to resolve this problem would be to carry out a population survey with use of genetic markers. Out of various genetic markers, the HLA system shows a significant association with PV. Ozawa et al. (1986) reported that there are strong associations between HLA (HLA-Cw6, Cw7, and DR7) antigens and PV in a Japanese population. These associations suggest that the PV susceptibility genes might be in linkage disequilibrium with these $H L A$ alleles. At present, there is no clear evidence of linkage between $H L A$ and the hypothesized PV susceptibility genes. For confirmation, the linkage may be verified by data on various markers such as HLA and complements (Dewald et al., 1983). If we made use of the nine multiplex families with PV in the current study and performed linkage analyses with the above genetic markers, we would be able to estimate gene frequencies of the hypothesized PV susceptibility genes.

Penetrance value ranged from 33 to $43 \%$ in the double recessive mode of inheritance. The finding of the reduced penetrance value was not surprising since environmental factors such as streptococcal infection appear to play a role in the etiology of PV (Asboe-Hansen, 1971).

In conclusion, some (about 20 to $38 \%$ ) of PV fitted a double recessive hypothesis and for the remaining larger proportion ( 62 to $80 \%$ ), the mode of inheritance for the susceptibility to PV remains unknown.

\footnotetext{
Acknowledgment This work was supported by a grant from the Uehara Memorial Foundation.
}

\section{REFERENCES}

Abele, D.C., Dobson, R.L., and Graham, J.B. 1963. Heredity and psoriasis: Study of a large family. Arch. Dermatol. 88: 38-47.

Asboe-Hansen, G. 1971. Psoriasis in childhood. In Psoriasis, Proceedings of the International Symposium: Stanford University 1971, Farber, E.M. and Cox, A.J., eds., Stanford University Press, California, pp. 53-59.

Dewald, G., Lange, C.E., Schmeel, E., and Kreysel, H.W. 1983. HLA-linked complement polymorphisms (C2, BF) in psoriasis. Arch. Dermatol. Res. 275: 301-304. 
Farber, E.M. and Nall, M.L. 1974. The natural history of psoriasis in 5,600 patients. Dermatologica 148: 1-18.

Henseler, T. and Christophers, E. 1985. Psoriasis of early and late onset: Characterization of two types of psoriasis vulgaris. J. Am. Acad. Dermatol. 13: 450-456.

Iselius, L. and Williams, W.R. 1984. Evidence for a major gene as well as multifactorial component and its implication for genetic counselling. Hum. Genet. 68: 73-76.

Lomholt, G. 1976. Environment and genetics in psoriasis. Ann. Clin. Res. 8: 290-297.

Ozawa, A., Ohkido, M., Inoko, H., Ando, A., Awataguchi, S., Sato, T., and Tsuji, K. 1986. DNA typing in psoriasis vulgaris. In $H L A$ in Asia-Oceania 1986. The Proceedings of the 3rd AsiaOceania Histocompatibility Workshop Conference, Aizawa, M., ed., Hokkaido University Press, Sapporo, pp. 779-782.

Pietrzyk, J.J., Turowski, G., Kapinska-Mrowka, M., and Rozanski, B. 1982. Family studies in psoriasis. I. Complex segregation analysis. Arch. Dermatol. Res. 273: 287-294.

Steinberg, A.G., Becker, S.W. Jr., Fitzpatrick, T.B., and Kierland, R.R. 1952. A further note on the genetics of psoriasis. Am. J. Hum. Genet. 4: 373-375.

Watson, E., Cann, H.M., Farber, E.M., and Nall, M.L. 1972. The genetics of psoriasis. Arch. Dermatol. 105: 197-207.

Yasuda, N. and Sasazuki, T. 1984. Complex segregation analysis for two locus model: Autosomal double recessive. Jpn. J. Human Genet, 29: 421-435. 